\title{
BMJ Open Depressive symptomatology, weight status and obesogenic risk among Australian adolescents: a prospective cohort study
}

\author{
Erin Hoare, ${ }^{1}$ Lynne Millar, ${ }^{1}$ Matthew Fuller-Tyszkiewicz, ${ }^{2,3}$ Helen Skouteris, ${ }^{2,3}$ \\ Melanie Nichols, ${ }^{1}$ Mary Malakellis, ${ }^{1}$ Boyd Swinburn, ${ }^{1,4}$ Steven Allender ${ }^{1}$
}

To cite: Hoare E, Millar L, Fuller-Tyszkiewicz M, et al. Depressive symptomatology, weight status and obesogenic risk among Australian adolescents: a prospective cohort study. BMJ Open 2016;6:e010072. doi:10.1136/bmjopen-2015010072

- Prepublication history for this paper is available online. To view these files please visit the journal online (http://dx.doi.org/10.1136/ bmjopen-2015-010072).

Received 22 September 2015 Revised 18 January 2016 Accepted 17 February 2016

CrossMark

\footnotetext{
${ }^{1}$ School of Health and Social Development, Deakin University, Geelong, Victoria, Australia

${ }^{2}$ School of Psychology, Deakin University, Geelong, Victoria, Australia

${ }^{3}$ Centre for Social and Early Emotional Development, Deakin University, Burwood, Victoria, Australia

${ }^{4}$ Population Nutrition and Global Health, University of Auckland, Auckland, New Zealand
}

Correspondence to Erin Hoare;

ejhoa@deakin.edu.au

\begin{abstract}
Objectives: Adolescence is a period of increased risk for mental health problems and development of associated lifestyle risk behaviours. This study examined cross-sectional and longitudinal associations between obesogenic risk factors, weight status, and depressive symptomatology in a cohort of Australian adolescents.

Design: Prospective cohort study.

Setting: The study used repeated measures data from the Australian Capital Territory (ACT) It's Your Move project, an Australian community-based obesity prevention intervention. Intervention effect was nonsignificant therefore intervention and comparison groups were combined in this study.
\end{abstract}

Participants: Total sample was 634 secondary school students (female $n=338$, male $n=296$ ) with mean age 13 years $(S D=0.6)$ at baseline (2012) and 15 years $(\mathrm{SD}=0.6)$ at follow-up (2014) recruited from 6 government secondary schools in the ACT.

Primary and secondary outcomes measures:

Primary outcome was depressive symptomatology measured by Short Mood and Feelings Questionnaire. Secondary outcomes were weight status, physical activity, screen time and diet related measures.

Results: Increased physical activity was associated to lower depressive symptomatology among males $(0 R=0.35, p<0.05)$. Sweet drink $(0 R=1.15, p<0.05)$ and takeaway consumption $(0 R=1.84, p<0.05)$ were associated with higher levels of depressive symptomatology among females at follow-up. Males who were classified as overweight or obese at baseline, and remained so over the study period, were at increased risk of depressive symptomatology at followup ( $b=1.63,95 \% \mathrm{Cl} 0.33$ to 2.92). Inactivity among males over the 2-year study period was predictive of higher depressive symptomatology scores at follow-up ( $b=2.55,95 \% \mathrm{Cl} 0.78$ to 4.32 ). For females, those who increased their consumption of takeaway foods during the study period were at increased risk for developing depressive symptomatology $(b=1.82,95 \% \mathrm{Cl}-0.05$ to 3.71 ).

Conclusions: There are multiple, probably complex, relationships between diet, physical activity and outcomes of obesity and mental health as well as

\section{Strengths and limitations of this study}

- This study examined a large-scale prospective sample of Australian adolescents and evaluated the complex associations between mental health, weight status and behaviours known to promote obesity.

- Risk factors underlying obesity have been shown to interact with mental health yet longitudinal associations are not yet well understood among adolescents.

- Between individual variability is limited by the repeat measures design and this is a significant strength of this research.

- Both diagnostic and continuous measures of depressive symptomatology are evaluated in this study, and this has been shown to be an appropriate measure for adolescent samples.

- Although previously validated in adolescent samples, self-report measures were used in this study and this poses validity concerns.

between the outcomes themselves. Healthier diets and increased physical activity should be foundations for healthier body weight and mental health.

Trial registration number: ACTRN12615000842561; Results.

\section{BACKGROUND}

In Australia, it has been shown that 1 in 4 young people will have had a depressive disorder by the end of adolescence ${ }^{1}$ and a similar proportion of children and adolescents aged 5-17 years are overweight or obese. ${ }^{2}$ Obesity and mental health issues often co-occur, ${ }^{3}$ and may share underlying risk factors including low physical activity, ${ }^{4-6}$ excess sedentary behaviours, ${ }^{78}$ and poor diet quality. ${ }^{79}$

Depressive symptomatology is the grouping of symptoms that categorise depression, 
including low mood and loss of pleasure in everyday activities that is beyond typical negative emotions that an individual would experience. ${ }^{10}$ Depressive symptomatology often first appears in adolescence and is likely to carry on into adulthood, ${ }^{11}$ manifesting as clinical depression later in life. ${ }^{12} \mathrm{~A}$ range of social, emotional, familial and biological factors are known contributors to onset of depression and depressive symptomatology and experiences can vary case by case. ${ }^{13}$ Prevalence estimates for adolescents vary widely, with community studies reporting estimates of depressive symptomatology ranging from $13 \%$ to $33 \% .^{10}{ }^{14-18}$ There is a large proportion of adolescents overall experiencing depressive symptomatology and studies aforementioned, and other research findings, ${ }^{19}{ }^{20}$ indicate that female adolescents are particularly affected.

There is a need for multidimensional approaches to adequately deal with the complexity of mental health issues, and this has given way to novel approaches to the underlying mechanisms of mental health issues including the influence of modifiable lifestyle behaviours. Our recent systematic review ${ }^{21}$ examined the associations between key obesogenic risk factors, including physical activity, sedentary behaviours, diet and weight status, with outcomes of depression among adolescent samples. Associations between overweight and obese weight status and depression appeared most commonly in females, ${ }^{22}{ }^{23}$ and improved mental health was revealed as a result of physical activity and sporting club participation among males. ${ }^{6}{ }^{24}$ Studies were characterised by non-representative samples with suboptimal study design and methodology. A key finding of the review was the need for more longitudinal studies to determine directionality of associations among weight status, depression and lifestyle risk factors.

Examining the influence of these risk factors is an important step in mental health research based on the known interactions between obesogenic behaviours and other non-communicable diseases, the comorbidity between such diseases and mental health ${ }^{3}$ and the major changes in lifestyle seen in the past century. ${ }^{25} \mathrm{An}$ understanding of these contributions will assist in developing interventions to maximise improvements in depression and other mental health outcomes that has often been overlooked in previous intervention studies in favour of obesity-related objectives. ${ }^{26}$

This study examines the depressive symptomatology outcomes, indicated by the Short Mood and Feelings Questionnaire (SMFQ), ${ }^{27}$ of the Australian Capital Territory It's Your Move (ACT IYM) project, a 3-year obesity prevention intervention that ran from 2012 to 2014 (inclusive). Baseline findings have previously been reported. ${ }^{16}$ The aim of the current study was twofold: (1) to re-examine cross-sectional associations at follow-up as an extension of the baseline findings; and (2) to evaluate longitudinal associations between depressive symptomatology at follow-up, and changes in obesogenic risk behaviours and weight status over the 2-year study period. Previous research and baseline findings indicated significant gender differences in these health issues, and therefore this study stratified analyses by gender to explore the unique associations for male and female adolescents. The ecological systems theory ${ }^{28}$ informed this study, as it assumes a broad range of factors operating at many levels (individual, family, community) occur simultaneously to impact on health outcomes.

\section{METHODS}

\section{Intervention design}

The ACT IYM was an intervention study aimed at preventing obesity through comprehensive school-based and community-based approaches to facilitating healthier lifestyles. The project was based on the successful It's Your Move! intervention in the Australian state of Victoria. The ACT IYM adopted a systems-based approach that aimed to target multiple levels within the school communities. The data for the evaluation of the ACT IYM were collected in May 2012 at baseline, and follow-up in May 2014. The intervention involved developing and implementing a healthy food at school policy, community capacity building within schools and community organisations, social marketing and programmes aimed at improving nutrition and physical activity systems.

To examine the ACT IYM intervention effect, a regression analysis was run with SMFQ scores as the outcome and the interaction between wave of data collection and study condition as the predictor plus relevant covariates. The interaction was found to be non-significant so the intervention and comparison groups have been combined in the current study (analysis not presented). Important limitations arising from this method are reported in the discussion section of this paper, however it was expected that controlling for school which participant attended was sufficient to account for potential confounding effects that may have occurred.

\section{Study design and participants}

The study design was quasi-experimental, repeated measures, using a longitudinal cohort follow-up. The intervention and comparison sites were in the Canberra region of the Australian Capital Territory (ACT) (population 357220 ). Schools were selected and invited to participate by the ACT Health Directorate. All six participating schools were government schools. Students in years 7 and 8 were invited to participate in baseline measures and no exclusion criteria were set.

\section{Consent and permissions}

The ACT IYM trial was registered with Australian New Zealand Clinical Trials Registry (ACTRN1261 5000842561). All students and their parents provided written consent prior to participation in the project. 


\section{Measures}

Depressive symptomatology was measured by the SMFQ, which contained 13 self-report items aimed at rapidly assessing depressive symptomatology for children and adolescents. ${ }^{27}$ The SMFQ comprises items relating to mood states, asking participants to indicate how they had been feeling or acting in the past 2 weeks. Full details on the development of the full questionnaire can be found in Angold et al. ${ }^{27}$ Statements such as 'I felt so tired I just sat around and did nothing' were rated on a three-point scale, where $0=$ not true, $1=$ sometimes, $2=$ true. This resulted in a possible score range of 0-26. Prior research has shown that the SMFQ has high internal consistency (Cronbach's $\alpha$ frequently $>0.85$ ) (23). The SMFQ items showed high internal reliability in baseline (Cronbach's $\mathrm{a}=0.88$ ) and follow-up (Cronbach's $\mathrm{a}=0.91$ ) analyses in this study. The SMFQ has been shown to correlate with other well-validated measures of depression including the Children's Depression Inventory and the Diagnostic Interview Schedule for Children's Depression Scale. ${ }^{27} 29$

Cross-sectional analyses used a dichotomous measure of depressive symptomatology, whereby depressive symptomatology was categorised as scores of 10 or above as consistent with previous studies using this instrument. ${ }^{30} 31$ An important aspect of this research was to re-examine cross-sectional analyses completed in 2012, ${ }^{16}$ at the 2014 time point. A dichotomous variable was used at baseline and again utilised in the current study for comparable cross-sectional analyses.

Longitudinal analyses used the total SMFQ score as a continuous variable as the outcome variable in this study. Research has supported using the total sum score of the SMFQ as a continuous measure of depressive symptom severity among adolescents. ${ }^{32-34}$ A continuous approach is more sensitive to change than evaluating whether an individual met or did not meet the SMFQ cut-off at either or both time points. The continuous measure allowed the magnitude of change to be evaluated as opposed to change in category.

The Adolescent Behaviours, Attitudes and Knowledge Questionnaire (ABAKQ $)^{35} 36$ contained self-report questions about physical activity, sedentary and dietary behaviours. The ABAKQ is a collection of questions from the 1995 Australian National Nutrition Survey, New Zealand 2002 National Children's Survey and National Health and Medical Research Council Dietary Key Indicators Study and has shown reliability and validity among adolescents. ${ }^{36}$ Physical activity behaviours were assessed by students' responses of either 'mostly played active games', 'mostly stood or walked' or 'mostly just sat down' during recess and lunch on the last school day. Students also reported whether they participated in 'sport, dance or active games' on the last school day with either 'yes' or 'no'. Students were classified as inactive/ low physical activity or moderately active/highly active, based on a value attributed to each response. Adolescents who were moderately/highly active played active games at least once during last school day and participated in sport, dance or active games. Those active not more than once on the last school day were categorised as inactive/low physical activity.

Leisure time screen-based sedentary behaviours were measured by items related to television viewing (including videos and DVDs) and three questions related to playing video games and using the computer (other than for homework), on a single school day, and Saturday and Sunday, then calculated to provide a daily estimate. This final estimate was then dichotomised according to whether it met $(\leq 2 \mathrm{~h} /$ day $)$ or exceeded $(>2 \mathrm{~h} /$ day) the recommendations for maximum screen time activities advised by the Australian Government for adolescents. $^{37}$

Diet-related items from the ABAKQ were used to measure consumption of fruit and vegetables, sweet drinks and takeaway food. Fruit and vegetable consumption was derived from participant's responses to how many servings of fruit/vegetables they consumed on the last school day, including those eaten at home. Responses were dichotomised into those participants who met WHO recommendations of minimum five servings ( $400 \mathrm{~g}$ ) of fruit and vegetables per day, and those who failed to meet this recommendation. ${ }^{38} \mathrm{~A}$ continuous index of average daily glasses of sweet drink consumed was derived by combining (summing) responses to two questions: one asked how many glasses of soft drink or energy drinks they had consumed on the last school day, and the other asked how many glasses of fruit drinks or cordial they had consumed on the last school day. Takeaway food consumption was measured by one question ('How often do you usually eat food from a takeaway?'), with five response options of 'once a month or less', '2-3 times a month', 'once a week', '2-3 times a week', or 'most days'. Owing to small proportions in some categories these data were dichotomised into 'less than once a month/2-3 times a month' or 'once a week/most days' to facilitate analysis.

Participants' height and weight were measured in a separate space, screened from other students, by gendermatched researchers trained in anthropometrics and body image protection. Measurements were taken in light clothing and without shoes. Weight was measured to the nearest $0.5 \mathrm{~kg}$ using electronic scales (A\&D Personal Precision Scale (UC-321)) and height was measured using a stadiometer (Charder Portable Stadiometer Height Rod HM200P). Body mass index (BMI) $\mathrm{z}$ score and weight status was calculated using the WHO 2007 reference age-specific BMI cut-offs. ${ }^{39}$ Given the small number of thin (low BMI) participants $(<2 \%)$, this category was combined with normal weight.

Demographic characteristics were self-reported in the ABAKQ including ethnicity, year level, and age. Participants were asked to indicate 'Which ethnic group do you most associate with?'. The responses options were European Australian, Indian, Chinese, Indigenous Australian, or Other. The number of participants who 
identified with ethnicities other than European Australian was low $(<3 \%)$ and was therefore combined with 'other' category. Parents' level of education that was used as a proxy for household socioeconomic position was requested on the parent's consent form that was completed prior to students' participation in data collection.

\section{STATISTICAL ANALYSIS}

Analyses were conducted using STATA release V.13.1 (Stata Corp., College Station, Texas, USA, 2013). All variables were checked for missing data, and in all cases there were $<5 \%$ missing. Little's Missing Completely at Random test ${ }^{40}$ was used to determine that data were missing completely at random, which was found to be non-significant $\left.\left(\chi^{2}(102, \mathrm{n}=634)=86.7, \mathrm{p}=0.86\right)\right)$ and therefore case-wise deletion was used where relevant. Histograms and calculations of skew and kurtosis values were used to check continuous variables for normality -normality assumptions met conventional standards. ${ }^{41}$ Demographic data were analysed using descriptive statistics, and any differences between males and females at baseline were tested for significance using independent sample Student t tests or Pearson's $\chi^{2}$ test (table 1 ). Changes in proportions from baseline to follow-up were tested for significance for within group (baseline to follow-up) using Newcombe's ${ }^{42}$ paired differences (table 2).

\section{Cross-sectional analyses}

Cross-sectional analyses were performed on the follow-up (postintervention) data collected in 2014 (baseline associations previously reported ${ }^{16}$ ) with all analyses stratified by gender. ORs were calculated for the association between each independent variable (IV) and the dependent variable; depressive symptomatology using a sequential multiple logistic regression with a forward stepwise approach. All models were tested for significance of covariates; school attended, age, and parent's level of education. Those covariates that were significant univariate predictors were retained in subsequent models. Model 1 reports the OR for each predictor IV entered into separate models with the outcome of depressive symptomatology at follow-up. The univariate cut-off $\mathrm{p}$ value for multivariable analyses was set at $\mathrm{p}<0.25$ to ensure maximum identification of predictor variables as recommended by prior research that reported $\mathrm{p}<0.05$ failed to identify variables known to be significant in multivariate models. ${ }^{44-46}$ Significant predictors found in model 1 were then entered in order of independent contribution (based on significance value at $\mathrm{p}<0.25)$ to univariate relationship, such that each represented a new iteration of the model. No further IVs were added to the model once all previously identified variables were included. Variance Inflation Factor indexes indicated no severe multicollinearity as all indexes met cut-off $<4$ as indicated by prior research. ${ }^{47}$

\section{Longitudinal analysis}

Separate multivariate regression models for males and females were completed on the outcome variable depressive symptomatology (total SMFQ score) at follow-up with each of the following predictor variables; change in physical activity, screen time, dietary behaviours and weight status. Change variables were based on selfreported obesogenic risk behaviours and objectively measured height and weight at baseline and follow-up. For example, an individual may have been inactive or active at both time points, or they might have become inactive at follow-up, or become active at follow-up giving four possible categories for each change variable. Baseline depressive symptomatology was controlled for as were various other potential confounders including the school the student attended, and parent's level of education. All results were considered significant at $\mathrm{p}<0.05$.

\section{RESULTS}

The overall baseline response rate was $56.5 \%$ and of these, approximately three quarters $(74.5 \%)$ participated in follow-up data collection. Reasons for participants lost to follow-up were refusal $(3.2 \%)$, unavailable $(7.2 \%)$, or moved elsewhere $(15.1 \%)$ and there were no

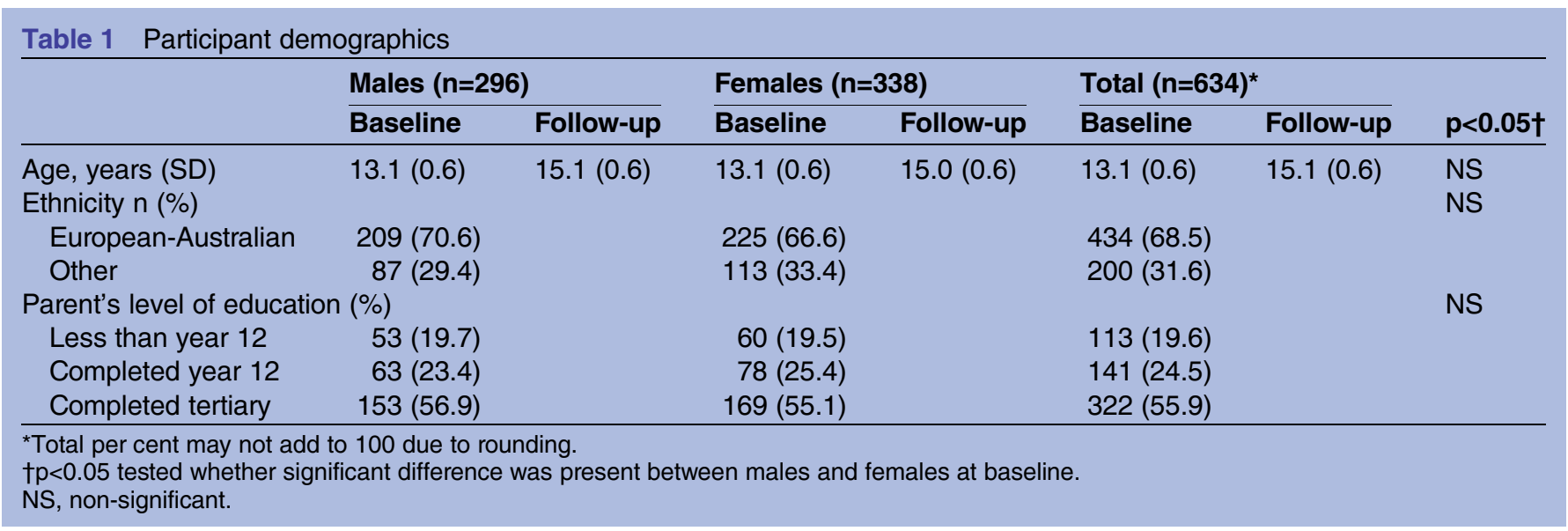


Table 2 Depressive symptomatology (Short Mood and Feelings Questionnaire, SMFQ), physical activity, sedentary behaviours, diet, weight status frequencies for males and female

\begin{tabular}{|c|c|c|c|c|c|c|}
\hline \multirow[b]{2}{*}{ Variable } & \multicolumn{2}{|l|}{ Males \% $(95 \% \mathrm{Cl})$} & \multicolumn{2}{|l|}{ Females \% (95\% Cl) } & \multirow{2}{*}{$\begin{array}{l}\text { Total \% }(95 \% \mathrm{Cl}) \\
\text { Baseline }\end{array}$} & \multirow[b]{2}{*}{ Follow-up } \\
\hline & Baseline & Follow-up & Baseline & Follow-up & & \\
\hline \multicolumn{7}{|l|}{ Depressive symptomatology } \\
\hline Cut-off $>10 * \%(95 \% \mathrm{Cl})$ & $13.2(9.3$ to 17.1$)$ & 8.9 (5.7 to 12.3$)$ & 21.9 (17.5 to 26.3$)$ & 36.5 (31.2 to 41.7$) \dagger$ & 17.8 (14.8 to 20.8$)$ & $23.6(20.2$ to 26.9$) \dagger$ \\
\hline Total score (0-26) mean (SD) & 4.8 (4.3 to 5.4$)$ & $4.6(4.1$ to 5.1$)$ & $6.8(6.3$ to 7.4$)$ & $9.0(8.4$ to 9.7$) \dagger$ & 5.89 (5.5 to 6.2$)$ & $6.96(6.5$ to 7.4$) \dagger$ \\
\hline Sedentary behaviour $\neq>2 \mathrm{~h} /$ day & 81.8 (77.3 to 86.2$)$ & $89.5(86.0$ to 93.1$) \dagger$ & $69.4(64.5$ to 74.4$)$ & $80.4(76.1$ to 84.6$) \dagger$ & 75.2 (71.8 to 78.6$)$ & $84.6(81.7$ to 87.4$) \dagger$ \\
\hline \multicolumn{7}{|c|}{ ( } \\
\hline Inactive/low active & 18.2 (14.3 to 23.0$)$ & 30.7 (25.8 to 36.2$) \dagger$ & 45.7 (40.0 to 51.0$)$ & $67.5(62.3$ to 72.2$) \dagger$ & 32.9 (29.3 to 36.6$)$ & $50.3(46.4$ to 54.2$) \dagger$ \\
\hline \multicolumn{7}{|c|}{ ( } \\
\hline Overweight/obese & 27.0 (21.9 to 32.1$)$ & 24.1 (19.1 to 29.1$)$ & 25.7 (21.1 to 30.4$)$ & 25.2 (20.5 to 29.9$)$ & 26.3 (22.9 to 29.8 ) & 24.7 (21.3 to 28.1$)$ \\
\hline \multicolumn{7}{|l|}{ Diet } \\
\hline $\begin{array}{l}\text { Failed to meet fruit and vegetable } \\
\text { recommendations }\end{array}$ & 44.9 (39.4 to 50.6$)$ & 42.9 (37.4 to 48.6$)$ & 55.0 (49.7 to 60.3$)$ & $48.8(43.5$ to 54.1$)$ & 50.3 (46.4 to 54.2$)$ & 46.1 (42.2 to 49.9$)$ \\
\hline \multicolumn{7}{|l|}{ Takeaway consumption } \\
\hline Once a week/most days & 26.4 (21.3 to 31.4$)$ & 34.8 (29.3 to 40.3$) \dagger$ & 19.3 (15.1 to 23.5$)$ & $26.6(21.9$ to 31.4$) \dagger$ & 22.6 (19.3 to 25.9 ) & $30.4(26.8$ to 34.0$) \dagger$ \\
\hline Sweet drink consumption ${ }^{\star *}$ mean (SD) & 2.3 (2.0 to 2.5$)$ & 2.3 (2.1 to 2.6$)$ & $1.6(1.5$ to 1.8$)$ & $1.6(1.4$ to 1.8$)$ & $1.9(1.8$ to 2.1$)$ & $1.9(1.7$ to 2.1$)$ \\
\hline
\end{tabular}


statistical differences between baseline characteristics between those who were followed up and those not followed up. Participants were $296(47 \%)$ males and 338 $(53 \%)$ females (table 1), with mean age at baseline being 13 years $(\mathrm{SD}=0.6$ years $)$ and 15 years $(\mathrm{SD}=0.6$ years $)$ at follow-up. Females experienced a significant increase in the proportion classified with depressive symptomatology from baseline to follow-up and in the total SMFQ score (table 2). Males and females experienced significant increases in daily hours of screen time, inactivity, and frequency of takeaway consumption.
Cross-sectional associations revealed physical activity level was associated significantly with depressive symptoms in univariate and multivariate models for males (table 3). Lower odds of depressive symptomatology $(\mathrm{OR}=0.35, \mathrm{p}<0.05)$ were found in male adolescents who were categorised in the moderately active/highly active category compared with low active or inactive males. For adolescent females, higher sweet drink consumption $(\mathrm{OR}=1.15, \quad \mathrm{p}<0.05)$ and takeaway consumption $(\mathrm{OR}=1.84, \mathrm{p}<0.05)$ were significantly associated with higher levels of depressive symptomatology after accounting for other possible contributing variables.

Table 3 Forward step-wise logistic regression ORs for outcome depressive symptomatology by predictor variables

\begin{tabular}{|c|c|c|c|c|c|c|c|}
\hline $\begin{array}{l}\text { Males } \\
\text { Variable }\end{array}$ & OR† & $95 \% \mathrm{Cl}$ & p Value* & $\begin{array}{l}\text { Females } \\
\text { Variable }\end{array}$ & OR & $95 \% \mathrm{Cl}$ & p Value* \\
\hline Univariate analysis & & & & Univariate analysis & & & \\
\hline Weight status $\ddagger$ & 2.01 & 0.84 to 4.83 & 0.12 & Weight status & 1.12 & 0.67 to 1.90 & 0.65 \\
\hline Physical activity§ & 0.29 & 0.13 to 0.65 & 0.003 & Physical activity & 1.37 & 0.85 to 2.21 & 0.19 \\
\hline Screen timeף & NA & NA & NA & Screen time & NA & NA & NA \\
\hline $\begin{array}{l}\text { Fruit and vegetable†† } \\
\text { consumption }\end{array}$ & 0.87 & 0.39 to 1.96 & 0.74 & $\begin{array}{l}\text { Fruit and vegetable } \\
\text { consumption }\end{array}$ & 0.85 & 0.54 to 1.34 & 0.49 \\
\hline Sweet drinksł‡ & 1.04 & 0.87 to 1.24 & 0.63 & Sweet drinks & 1.17 & 1.04 to 1.32 & 0.008 \\
\hline $\begin{array}{l}\text { Takeaway } \\
\text { consumption§§ }\end{array}$ & 1.18 & 0.51 to 2.72 & 0.65 & $\begin{array}{l}\text { Takeaway } \\
\text { consumption }\end{array}$ & 1.91 & 1.16 to 3.14 & 0.01 \\
\hline Schoolๆা & 0.84 & 0.67 to 1.05 & 0.14 & School & 1.06 & 0.93 to 1.20 & 0.40 \\
\hline Age††† & 0.83 & 0.44 to 1.55 & 0.56 & Age & 1.30 & 0.92 to 1.84 & 0.14 \\
\hline $\begin{array}{l}\text { Parent's education } \ddagger \ddagger \ddagger \\
\text { Multivariate analysis§§§§ }\end{array}$ & 0.69 & 0.42 to 1.13 & 0.14 & $\begin{array}{l}\text { Parent's education } \\
\text { Multivariate analysis }\end{array}$ & 0.99 & 0.74 to 1.34 & 0.96 \\
\hline & & & p Value ${ }^{* *}$ & & & & p Value $e^{\star \star}$ \\
\hline Model 1 & & & & Model 1 & & & \\
\hline Physical activity & 0.31 & 0.13 to 0.70 & 0.005 & Sweet drinks & 1.15 & 1.02 to 1.30 & 0.02 \\
\hline Weight status & 1.89 & 0.77 to 4.63 & 0.16 & $\begin{array}{l}\text { Takeaway } \\
\text { consumption }\end{array}$ & 1.74 & 1.05 to 2.90 & 0.03 \\
\hline $\begin{array}{l}\text { Pseudo } \mathrm{R}^{2} \\
\text { Model } 2\end{array}$ & \multicolumn{3}{|c|}{$0.06(p<0.005)$} & $\begin{array}{l}\text { Pseudo } R^{2} \\
\text { Model } 2\end{array}$ & \multicolumn{3}{|l|}{$0.03(p<0.002)$} \\
\hline Physical activity & 0.31 & 0.13 to 0.74 & 0.008 & Sweet drinks & 1.16 & 1.02 to 1.30 & 0.01 \\
\hline Weight status & 1.88 & 0.76 to 4.61 & 0.17 & $\begin{array}{l}\text { Takeaway } \\
\text { consumption }\end{array}$ & 1.72 & 1.03 to 2.86 & 0.04 \\
\hline School & 0.87 & 0.68 to 1.11 & 0.26 & Age & 1.25 & 0.87 to 1.79 & 0.23 \\
\hline Pseudo $\mathrm{R}^{2}$ & \multirow{2}{*}{\multicolumn{3}{|c|}{$0.07(p<0.008)$}} & Pseudo $\mathrm{R}^{2}$ & \multirow{2}{*}{\multicolumn{3}{|c|}{$0.03(p<0.004)$}} \\
\hline Model 3 & & & & Model 3 & & & \\
\hline Physical activity & 0.35 & 0.14 to 0.86 & 0.02 & Sweet drinks & 1.15 & 1.02 to 1.31 & 0.02 \\
\hline Weight status & 1.95 & 0.78 to 4.88 & 0.15 & $\begin{array}{l}\text { Takeaway } \\
\text { consumption }\end{array}$ & 1.84 & 1.08 to 3.12 & 0.02 \\
\hline School & 0.85 & 0.66 to 1.10 & 0.24 & Age & 1.40 & 0.96 to 2.02 & 0.08 \\
\hline Parent's education & 0.69 & 0.40 to 1.16 & 0.16 & Physical activity & 1.48 & 0.90 to 2.46 & 0.13 \\
\hline Pseudo $\mathrm{R}^{2}$ & \multicolumn{3}{|c|}{$0.08(p<0.01)$} & Pseudo $\mathrm{R}^{2}$ & $0.08(p<0.01)$ & & \\
\hline
\end{tabular}

Bold indicates *significance $p<0.25$ for univariate analysis ** $p<0.05$ for multivariate analysis (models $1-3$ ).

tOR for being classified with depressive symptomatology (SMFQ $\geq 10$ ).

$\ddagger$ Overweight/obesity compared with normal weight defined by WHO age-specific and sex-specific cut-offs based on BMI z scores.

$\S$ Low active/inactive compared with moderate or highly active.

TExceeded Australian Government daily screen-based media guidelines of $2 \mathrm{~h}$ or less per day compared with meeting recommendations.

††Did not meet WHO guidelines of $400 \mathrm{~g} /$ day compared with meeting recommendations.

$\ddagger \ddagger O n e$ glass increase per day.

$\S \S D$ aily/weekly consumption compared with monthly consumption or less.

IT School that participant attended.

†††Age in years.

$\ddagger \ddagger \ddagger$ Parent's level of education.

$\S \S \S$ Forward stepwise model, where each predictor variable is added in order of significance in contribution to depressive symptomatology

BMI, body mass index; NA, not applicable; SMFQ, Short Mood and Feelings Questionnaire. 
Screen time was deemed statistically inappropriate due to low cell size and possibility of complete separation and was therefore removed from these, and consequential models.

Longitudinal analyses revealed males who were classified as overweight or obese at baseline and remained overweight/obese at follow-up reported significantly increased depressive symptomatology total scores $(b=1.63,95 \%$ CI 0.33 to 2.92) compared with males who were normal weight at both time points (table 4). Males who were classified as inactive at both time points also experienced significantly increased depressive symptomatology scores ( $b=2.55,95 \%$ CI 0.78 to 4.32 ) compared with active males. For females, those who reported monthly consumption of takeaway foods or less at baseline but increased to weekly or daily consumption at follow-up had increased odds of depressive symptomatology at follow-up $(b=1.82,95 \%$ CI -0.05 to 3.71). All models accounted for baseline depressive symptomatology total scores.

\section{DISCUSSION}

The aim of this study was to examine follow-up crosssectional and the longitudinal associations between obesogenic risk behaviours and weight status and depressive symptomatology. This study demonstrated that some risk factors for obesity were concurrent and longitudinal predictors of depressive symptomatology among male and female adolescents. Ecological systems theory underpins this discussion, assuming that findings represent complex interactions between a range of factors operating at many levels surrounding an individual. Explanations for the observed results are made with respect to such complexity.

Depressive symptomatology prevalence was consistent with previous literature as were the gender differences found in this study. Specifically, it has been reported that depressive symptomatology increases during adolescence, ${ }^{48}$ and that increases are more common in groups of females, while stable or decreasing prevalence was more common among males. ${ }^{19} 20$ Our results identified a large proportion of young women experiencing difficulties, or at risk for developing symptomatology in older adolescence, and support is needed for this vulnerable group.

It is possible that depressive symptomatology measures may not adequately capture the proportion of males suffering. It has been reported that there may be conflict between historical male gender role expectations and acknowledgement of personal problems, emotional awareness and vulnerability that characterises reporting mental health issues such as depression. ${ }^{49}$ Males may be less likely to seek mental health support services and

Table 4 Unstandardised coefficient $(95 \% \mathrm{Cl}$ ) for outcome depressive symptomatology (2014) by changes in predictor variables from 2012 to 2014, controlled for school which participant attended and parent's level of education

\begin{tabular}{|c|c|c|c|c|c|}
\hline Baseline (2012) & Follow-up (2014) & $\begin{array}{l}\text { Males } \\
\text { b* }^{*}\end{array}$ & $95 \% \mathrm{Cl}$ & $\begin{array}{l}\text { Females } \\
\text { b }\end{array}$ & $95 \% \mathrm{Cl}$ \\
\hline \multicolumn{6}{|l|}{ Weight status $\dagger$} \\
\hline Overweight/obese & Overweight/obese & 1.63 & 0.33 to 2.92 & -0.16 & -1.93 to 1.62 \\
\hline Normal & Overweight/obese & -0.11 & -2.77 to 2.54 & 0.92 & -1.87 to 3.71 \\
\hline Overweight/obese & Normal & 1.16 & -1.01 to 3.33 & 1.74 & -1.21 to 4.71 \\
\hline Normal & Normal & 1.00 & Reference & 1.00 & Reference \\
\hline \multicolumn{6}{|l|}{ Physical activity } \\
\hline Inactive & Inactive & 2.55 & 0.78 to 4.32 & -0.39 & -2.19 to 1.41 \\
\hline Active & Inactive & -0.40 & -1.69 to 0.89 & 0.96 & -0.92 to 2.83 \\
\hline Inactive & Active & -0.64 & -2.53 to 1.25 & 1.56 & -1.04 to 4.18 \\
\hline Active & Active & 1.00 & Reference & 1.00 & Reference \\
\hline \multicolumn{6}{|c|}{ Fruit and vegetable } \\
\hline Did not meet & Did not meet & 0.46 & -0.89 to 1.81 & -0.62 & -2.32 to 1.07 \\
\hline Met & Did not meet & -0.55 & -2.03 to 0.93 & -1.20 & -3.31 to 0.91 \\
\hline Did not meet & Met & 0.62 & -0.80 to 2.04 & -1.30 & -3.22 to 0.62 \\
\hline Met & Met & 1.00 & Reference & 1.00 & Reference \\
\hline \multicolumn{6}{|l|}{ Sweet drink§ } \\
\hline Change in mean & & -0.11 & -0.34 to 0.11 & 0.15 & -0.17 to 0.45 \\
\hline \multicolumn{6}{|c|}{ Takeaway consumption } \\
\hline Weekly/daily & Weekly/daily & 0.26 & -1.12 to 1.63 & 0.66 & -1.57 to 2.89 \\
\hline Monthly or less & Weekly/daily & 0.90 & -0.57 to 2.37 & 1.82 & -0.05 to 3.71 \\
\hline Weekly/daily & Monthly or less & -0.50 & -2.57 to 1.58 & -1.16 & -3.54 to 1.21 \\
\hline Monthly or less & Monthly or less & 1.00 & Reference & 1.00 & Reference \\
\hline
\end{tabular}

Bold indicates significance $\mathrm{p}<0.05$.

${ }^{*}$ Coefficient for total Short Mood and Feelings Questionnaire (SMFQ) score at follow-up.

†Defined by WHO age-specific and sex-specific cut-offs based on body mass index z scores.

$\ddagger W H O$ guidelines of $400 \mathrm{~g} /$ day.

$\S$ Change in daily mean sweet drink consumption from baseline to follow-up. 
there are higher rates of suicide in the male population compared with the female population. ${ }^{50}$ Although the increased risk for female adolescents is reported in this study and elsewhere, the determinants of this gender difference are far from established and it is therefore important to examine female and male experiences to ensure that those in need of mental health support are not overlooked.

Physical activity in males was cross-sectionally and longitudinally predictive of depressive symptomatology. Previous studies have demonstrated that sporting club involvement and level of physical exercise has been protective of mental health in male adolescent populations. ${ }^{6}{ }^{24}$ There is also evidence to suggest that physical activity significantly reduces the risk for future increases in depressive symptomatology in female adolescents. ${ }^{51}$ Overall a greater proportion of males compared with females were classified as moderately or highly active and this may provide opportunity for males to develop skills (self-esteem, community involvement, resilience) that are protective from negative emotions that characterise depression. ${ }^{52}$ Conversely, adolescent males who are inactive may lack motivation to become involved in such activities and may not experience such emotional benefit that over time leads to increased depressive symptomatology. Females were at such higher risk in experiencing depressive symptomatology that no benefits may have been observed through participating in physical activity, or that if benefits did exist, then another undetermined variable that was specific to females had greater impact.

Although prevalence of weight status was stable over time for male and female adolescents, males who were overweight or obese at baseline and remained overweight or obese at follow-up experienced significantly higher depressive symptomatology scores. This finding builds on those found at baseline that demonstrated increased odds for depressive symptomatology in overweight and obese males in 2012 after accounting for other obesogenic risk factors. Previous research has shown the link between overweight/obese weight status and depression, ${ }^{3}$ however this relationship appears to be more prominent in female populations. ${ }^{22}{ }^{23}$ Sensitivity to body image and weight-based mental health concerns have most commonly been directed specifically towards females, ${ }^{53}$ however the current findings demonstrate that males experiencing overweight and obesity are in need of mental health support. Further research is recommended, particularly considering the growing body of research suggesting it is weight perception as opposed to weight status itself, which impacts on mental health in adolescents. ${ }^{54} 55$

Sweet drink and takeaway consumption has been linked to depression in adolescents in previous research. ${ }^{756}$ Adequate nutrition is well established as a prerequisite for brain functioning and mood regulation, ${ }^{57}$ as is appetite change as a symptom of clinical depression. ${ }^{58}$ One previous study ${ }^{59}$ found stronger associations between consumption of sweet and highsaturated fat foods (chocolates, cakes/biscuits/pastries) among women experiencing depressive symptoms compared with those not experiencing symptoms. In contrast, significant associations were found between sweetened and fatty foods in males without depressive symptomatology and no significant associations for those with depressive symptoms. Importantly, this current study demonstrated that increased frequency of takeaway consumption over the study period among females significantly predicted depressive symptomatology at follow-up, irrespective of baseline depressive symptomatology. Females have been shown to be more likely to exhibit extreme eating behaviours ${ }^{60} 61$ and this relationship may be a result of a stronger dietary behavioural response to negative emotional experiences that characterises depression. Further research is needed to explicate the complex effects of the broad range and change in dietary patterns during adolescence. ${ }^{62}$ Given the increased risk for depression among female adolescents, and the known negative health outcomes of high-energy dense foods ${ }^{63}$ commonly bought at takeaway outlets, this finding warrants further exploration.

Some limitations are important in the interpretation of the results found in this study. The main limitation was that the underlying study was a quasi-experimental design, and intervention and comparison groups were combined in this current study. Individuals in intervention schools were exposed to the ACT IYM programme. The programme aimed to improve nutrition and physical activity behaviours, and this was expected to impact on key variables analysed in this research. Despite this possible effect, initial analyses demonstrated a null intervention effect on depressive symptomatology and it was accepted that controlling for school participant attended was appropriate.

The main variables of interest were based on selfreport responses and this may have resulted in numerous biases. The participants of this study would have some understanding of what defines a healthy lifestyle and this may have introduced social desirability bias to some responses. Biases may have occurred as participants were asked to recall behaviours 'on the last school day'. This may have limited the extent to which overall lifestyle behaviours can be estimated, as it is based on a single day's estimate and may not represent behaviours during the weekend or holidays. This wording was selected as it allowed specific response and ensures a more user-friendly way of recalling information, appropriate for younger respondents. ${ }^{35}$ Dichotomising participants into inactive/less active and moderately/highly active was another source of potential bias, as the influence of variations in activity levels and intensity may not have been accurately reflected in the analysis of two categories. Such biases were accepted as an inevitable outcome of examining a broad range of obesogenic behaviours and a more comprehensive analysis of physical activity is recommended for future research, 
particularly given the significant relationship found with depressive symptomatology.

An additional limitation was that a daily average of time spent using screen time for leisure was estimated based on responses to questions for weekdays and Saturday and Sunday. It is expected this variable may have provided a more comprehensive indication of activity, compared with the items used to categorise physical activity. Despite its various limitations the ABAKQ was an appropriate tool for this study given it is easy to administer to large groups, it is designed specifically for adolescent populations, and has been used previously to examine a broad range of diet and activity related behaviours. $^{3564}$

There was a large non-participation rate at baseline (52\% response rate). Although there were no significant differences in baseline characteristics between those followed up and those not followed up, adolescents experiencing mental or physical health conditions may have been less inclined to participate in this study due to physical or emotional symptoms associated with their condition. These groups may have therefore been under-represented in this sample. The participation rate obtained was in line with expectations, based on previous community-based studies of similar demographics. ${ }^{63}$

Factors beyond lifestyle behaviours and weight status may have contributed to depressive symptomatology, such as previous episodes of depression, family history of depression or comorbidity of other diseases. The full range of potential influences were not measured in the current study and therefore not controlled for in analyses, which presents a further limitation to interpretation of the findings. This study is strengthened by repeat measures design, therefore eliminating the impact of between individual variability.

\section{CONCLUSION}

Findings from this study and others indicate that adolescents experience high levels of depression, obesity and exhibit poor dietary and physical activity behaviours. It is acknowledged that the true relationships between these health issues are likely to be multiple and complex, and most likely differ by population including by gender. This study supports addressing diet and physical activity as the foundation for obesity and also mental health outcomes among the adolescent population. It is recommended that intervention studies be considered highest priority for research and that mental health is evaluated alongside obesity indicators with sensitivity towards the complexity of the relationship between these health issues.

Acknowledgements The authors thank all the staff and students for participating in the project. They extend their special thanks to the IYM school coordinators, Cal Chikwendu and ACT Health. This programme was a joint Australian, State and Territory Government initiative under the National Partnership Agreement on Preventative Health. The ACT IYM was funded by the Australian Capital Territory Government.
Contributors EH participated in the conception and design of this study, analysed and interpreted the data, and drafted the manuscripts. LM participated in the conception and design of this study and the ACT IYM project, analysed and interpreted the data, and critically revised the manuscripts. MF-T analysed and interpreted the data, critically revised the manuscripts and approved the final version. HS participated in the conception and design of this study, critically revised the manuscripts and approved the final version. MN participated in the conception and design of this study and the ACT IYM project and revised the manuscripts and approved the final version. MM led data collection, data entry and data cleaning, and revised and approved the final manuscript. BS and SA participated in conception and design of the ACT IYM project, revised the manuscripts and approved the final version.

Funding The study was funded by the Australian Capital Territory Government. SA is supported by funding from an Australian National Health and Medical Research Council/Australian National Heart Foundation Career Development Fellowship (APP1045836). He is supported by US National Institutes of Health grant titled Systems Science to Guide Whole-ofCommunity Childhood Obesity Interventions (1R01HL115485-01A1). SA and LM are researchers within a National Health and Medical Research Council Centre for Research Excellence in Obesity Policy and Food Systems (APP1041020). LM is supported by an Alfred Deakin Postdoctoral Fellowship.

Competing interests None declared.

Ethics approval The study was approved by the Deakin University Human Research Ethics Committee (EC 2012-2015) and Australian Capital Territory Government Education and Training Directorate (reference number 2012/ 00545-1).

Provenance and peer review Not commissioned; externally peer reviewed.

Data sharing statement No additional data are available.

Open Access This is an Open Access article distributed in accordance with the Creative Commons Attribution Non Commercial (CC BY-NC 4.0) license, which permits others to distribute, remix, adapt, build upon this work noncommercially, and license their derivative works on different terms, provided the original work is properly cited and the use is non-commercial. See: http:// creativecommons.org/licenses/by-nc/4.0/

\section{REFERENCES}

1. Mission Australia. National survey of young Australians 2007: key and emerging issues. Mission Australia, 2007.

2. National Health and Medical Research Council. Clinical practice guidelines for the management of overweight and obesity in adults, adolescents and children in Australia. Melbourne, Australia: NHMRC, 2013.

3. Luppino FS, de Wit LM, Bouvy PF, et al. Overweight, obesity, and depression: a systematic review and meta-analysis of longitudinal studies. Arch Gen Psychiatry 2010;67:220-9.

4. Adeniyi AF, Okafor NC, Adeniyi CY. Depression and physical activity in a sample of Nigerian adolescents: levels, relationships and predictors. Child Adolesc Psychiatry Ment Health 2011;5:16.

5. Arbour-Nicitopoulos KP, Faulkner GE, Irving HM. Multiple health-risk behaviour and psychological distress in adolescence. J Can Acad Child Adolesc Psychiatry 2012;21:171-8.

6. Desha LN, Ziviani JM, Nicholson JM, et al. Physical activity and depressive symptoms in American adolescents. J Sport Exerc Psychol 2007;29:534-43.

7. Robinson M, Kendall GE, Jacoby $P$, et al. Lifestyle and demographic correlates of poor mental health in early adolescence. $J$ Paediatr Child Health 2011;47:54-61.

8. Pantic I, Damjanovic A, Todorovic J, et al. Association between online social networking and depression in high school students: behavioral physiology viewpoint. Psychiatr Danub 2012;24:90-3.

9. Jacka FN, Kremer PJ, Leslie ER, et al. Associations between diet quality and depressed mood in adolescents: results from The Australian Healthy Neighbourhoods Study. Aust N Z J Psychiatry 2010;44:435-42.

10. Ayuso-Mateos JL, Nuevo R, Verdes E, et al. From depressive symptoms to depressive disorders: the relevance of thresholds. Br J Psychiatry 2010;196:365-71. 
11. Kessler RC, Amminger GP, Aguilar-Gaxiola S, et al. Age of onset of mental disorders: a review of recent literature. Curr Opin Psychiatry 2007;20:359

12. Fergusson DM, Horwood LJ, Ridder EM, et al. Subthreshold depression in adolescence and mental health outcomes in adulthood. Arch Gen Psychiatry 2005;62:66-72.

13. Beck A, Brad A. Depression: causes and treatment. University of Pennsylvania Press, 2009

14. Lawrence D, Johnson S, Hafekost J, et al. The mental health of children and adolescents. Report on the second Australian Child and Adolescent Survey of Mental Health and Wellbeing. Canberra: Department of Health, 2015

15. Boyd CP, Kostanski M, Gullone E, et al. Prevalence of anxiety and depression in Australian adolescents: comparisons with worldwide data. J Genet Psychol 2000;161:479.

16. Hoare E, Millar L, Fuller-Tyszkiewicz M, et al. Associations between obesogenic risk and depressive symptomatology in Australian adolescents: a cross-sectional study. J Epidemiol Community Health 2014;68:767-72.

17. Albert N, Beck AT. Incidence of depression in early adolescence: a preliminary study. J Youth Adolesc 1975;4:301-7.

18. McKenzie DP, Toumbourou JW, Forbes AB, et al. Predicting future depression in adolescents using the Short Mood and Feelings Questionnaire: a two-nation study. J Affect Disord 2011;134: 151-9.

19. Ge X, Conger RD, Elder GH Jr. Pubertal transition, stressful life events, and the emergence of gender differences in adolescent depressive symptoms. Dev Psychol 2001;37:404-17.

20. Angold A, Erkanli A, Loeber R, et al. Disappearing depression in a population sample of boys. J Emotion Behav Disord 1996;4: 95-104.

21. Hoare E, Skouteris H, Fuller-Tyszkiewicz M, et al. Associations between obesogenic risk factors and depression among adolescents: a systematic review. Obes Rev 2014;15:40-51.

22. Needham BL, Crosnoe R. Overweight status and depressive symptoms during adolescence. J Adolesc Health 2005;36:48-55.

23. Anderson SE, Cohen P, Naumova EN, et al. Adolescent obesity and risk for subsequent major depressive disorder and anxiety disorder: Prospective evidence. Psychosom Med 2007;69:740-7.

24. Sund AM, Larsson B, Wichstrøm L. Role of physical and sedentary activities in the development of depressive symptoms in early adolescence. Soc Psychiatry Psychiatr Epidemiol 2011:46:431-41.

25. Jacka FN, Berk M. Depression, diet and exercise. Med J Aust 2013;199:S21-3.

26. Hoare E, Fuller-Tyszkiewicz M, Skouteris $\mathrm{H}$, et al. Systematic review of mental health and well-being outcomes following community-based obesity prevention interventions among adolescents. BMJ Open 2015;5:e006586.

27. Angold A, Costello EJ, Messer SC, et al. Development of a short questionnaire for use in epidemiological studies of depression in children and adolescents. Int $J$ Methods Psychiatr Res 1995;5:237-49.

28. Brofenbrenner U. Toward a experimental ecology of human development. Am Psychol 1977;513

29. Turner N, Joinson C, Peters TJ, et al. Validity of the Short Mood and Feelings Questionnaire in late adolescence. Psychol Assess 2014;26:752-62.

30. Chipman $\mathrm{P}$, Jorm AF, Prior M, et al. No interaction between the serotonin transporter polymorphism (5-HTTLPR) and childhood adversity or recent stressful life events on symptoms of depression: Results from two community surveys. Am J Med Genet $B$ Neuropsychiatr Genet 2007;144B:561-5.

31. Kuo ES, Stoep AV, Stewart DG. Using the short Mood and Feelings Questionnaire to detect depression in detained adolescents. Assessment 2005; 12:374-83.

32. Lundervold AJ, Breivik K, Posserud MB, et al. Symptoms of depression as reported by Norwegian adolescents on the Short Mood and Feelings Questionnaire. Front Psychol 2013;4:613.

33. Glaser B, Gunnell D, Timpson NJ, et al. Age- and puberty-dependent association between IQ score in early childhood and depressive symptoms in adolescence. Psychol Med 2011:41:333-43.

34. Angold A, Erkanli A, Silberg J, et al. Depression scale scores in 8-17-year-olds: effects of age and gender. J Child Psychol Psychiatry 2002;43:1052-63.

35. Lacy KE, Allender SE, Kremer PJ, et al. Screen time and physical activity behaviours are associated with health-related quality of life in Australian adolescents. Qual Life Res 2012;21:1085-99.

36. Mathews L, Simmons A, Sanigorski A, et al. It's Your Move: implementation report 5-evaluation. Geelong, Victoria: Deakin University, 2009.
37. Department of Health and Ageing. Australia's physical activity recommendations for 12-18-year-olds. Canberra, ACT: Department of Health and Ageing, 2004.

38. World Health Organization. Fruit and vegetables for health: report of a joint FAO/WHO workshop 1-3 September 2004, Kobe. Japan, Switzerland: World Health Organisation, 2004.

39. de Onis M, Onyango AW, Borghi E, et al. Development of a WHO growth reference for school-aged children and adolescents. Bull World Health Organ 2007;85:660-7.

40. Little RJ. A test of missing completely at random for multivariate data with missing values. J Am Stat Assoc 1988;83:1198-202.

41. Curran PJ, West SG, Finch JF. The robustness of test statistics to nonnormality and specification error in confirmatory factor analysis. Psychol Methods 1996;1:16.

42. Newcombe RG. Interval estimation for the difference between independent proportions: comparison of eleven methods. Stat Med 1998;17:873-90.

43. World Health Organization. WHO Reference 2007; Growth Reference Data for 5-19 years. Geneva: WHO, 2010.

44. Bendel RB, Afifi AA. Comparison of stopping rules in forward "stepwise" regression. J Am Stat Assoc 1977;72:46-53.

45. Mickey RM, Greenland S. The impact of confounder selection criteria on effect estimation. Am J Epidemiol 1989;129:125-37.

46. Bursac Z, Gauss CH, Williams DK, et al. Purposeful selection of variables in logistic regression. Source Code Biol Med 2008;3:17.

47. Tabachnick BG, Fidell LS. Using multivariate statistics (6th international edition). Pearson, 2013.

48. Garber J, Keiley MK, Martin NC. Developmental trajectories of adolescents' depressive symptoms: predictors of change. J Consult Clin Psychol 2002;70:79.

49. Good GE, Wood PK. Male gender role conflict, depression, and help seeking: Do college men face double jeopardy? J Couns Dev 1995;74:70-5

50. Hawton K. Sex and suicide gender differences in suicidal behaviour. Br J Psychiatry 2000;177:484-5.

51. Jerstad SJ, Boutelle KN, Ness KK, et al. Prospective reciprocal relations between physical activity and depression in female adolescents. J Consult Clin Psychol 2010;78:268-72.

52. Babiss LA, Gangwisch JE. Sports participation as a protective factor against depression and suicidal ideation in adolescents as mediated by self-esteem and social support. $J$ Dev Behav Pediatr 2009;30:376-84.

53. Carpenter KM, Hasin DS, Allison DB, et al. Relationships between obesity and DSM-IV major depressive disorder, suicide ideation, and suicide attempts: results from a general population study. $A m \mathrm{~J}$ Public Health 2000;90:251.

54. Hayward J, Millar L, Petersen S, et al. When ignorance is bliss: weight perception, body mass index and quality of life in adolescents. Int J Obes (Lond) 2014;38:1328-34.

55. Roberts RE, Duong HT. Perceived weight, not obesity, increases risk for major depression among adolescents. J Psychiatr Res 2013:47:1110-17.

56. Jacka F, Rothon C, Taylor S, et al. Diet quality and mental health problems in adolescents from East London: a prospective study. Soc Psychiatry Psychiatr Epidemiol 2013:1-10.

57. Bodnar LM, Wisner KL. Nutrition and depression: implications for improving mental health among childbearing-aged women. Biol Psychiatry 2005;58:679-85

58. American Psychiatric Association. Diagnostic and statistical manual of mental disorders (DSM-5®). American Psychiatric Pub, 2013.

59. Camilleri GM, Méjean C, Kesse-Guyot E, et al. The associations between emotional eating and consumption of energy-dense snack foods are modified by sex and depressive symptomatology. J Nutr 2014;144:1264-73.

60. Mikolajczyk RT, El Ansari W, Maxwell AE. Food consumption frequency and perceived stress and depressive symptoms among students in three European countries. Nutr J 2009;8:31.

61. Rolls BJ, Fedoroff IC, Guthrie JF. Gender differences in eating behavior and body weight regulation. Health Psychol 1991;10:133.

62. Neumark-Sztainer D, Story M, Perry C, et al. Factors influencing food choices of adolescents: findings from focus-group discussions with adolescents. J Am Diet Assoc 1999;99:929-37.

63. Epstein LH, Paluch RA, Beecher MD, et al. Increasing healthy eating vs. reducing high energy-dense foods to treat pediatric obesity. Obesity (Silver Spring) 2008;16:318-26.

64. Millar L, Kremer P, de Silva-Sanigorski A, et al. Reduction in overweight and obesity from a 3-year community-based intervention in Australia: the It's Your Move! Project. Obes Rev 2011;12(Suppl 2):20-8. 